\title{
Pengaruh Ideologi Visual dalam Penciptaan Positioning Clothing (Studi Kasus: Unkl/347-Bandung)
}

\author{
Monica Hartanti \\ Desain Komunikasi Visual, Fakultas Seni Rupa dan Desain \\ Universitas Kristen Maranatha, Bandung, Indonesia \\ E-mail: if_269@yahoo.com
}

\begin{abstract}
Abstrak
Keunikan dan ciri khas Clothing yang merupakan salah satu kategori fashion telah memunculkan pengertian fashion sebagai sebuah ideologi, dimana didalamnya menjamin berfungsinya sebuah sistem dominan dan dominasi pada sebuah tatanan sosial. Melalui penelitian analisis deskriptif kualitatif ini akan diketahui ideologi visual pada sebuah produk clothing yang dibentuk oleh produsen dimata konsumennya. Dimana akhirnya hal tersebut mampu membentuk positioning produk yang bersangkutan. Hasil penelitian ini mengungkapkan bahwa kemunculan Ideologi dalam clothing didasarkan pada idealisme pencipta produk clothing tersebut. Terbentuknya idealisme tersebut tidak terlepas dari peranan komunitas sebagai medium yang mendukung terserapnya ideologi tersebut sebagai sebuah karakteristik kelompok tertentu. Hal tersebut mengungkapkan bahwa Ideologi visual merupakan salah satu faktor penting pembentukan positioning sebuah produk yang tercipta karena adanya diferensiasi produk yang mendukungnya.
\end{abstract}

Kata kunci: Clothing, Ideologi, Positioning.

\begin{abstract}
The Uniqueness and characteristics of Clothing, two of the fashion categories have created the understanding of fashion as an ideology, which ensures the functioning of dominant and dominance systems in a social order. Through the analysis of qualitative descriptive research will be known the visual ideology of a clothing product formed by producers in the eyes of consumers. In the end it is capable of forming the product positioning concerned. The results of of this research reveals the emergence of Ideology in clothing, based on the ideals of the creator of the clothing products. The formation of these ideals cannot be separated from the role of the community as a medium that supports the absorption of the ideology as the characteristic of a particular group. It reveals that visual ideology is one of the important factors that establishes the positioning of a product, which is created because of the existence of product differentiation that supports it.
\end{abstract}

Keywords: Clothing, Ideology, Positioning.

\section{Pendahuluan}

Bandung, dalam 10 tahun ini merupakan salah satu kota industri kreatif yang sangat berkembang di Indonesia. Clothing menjadi salah satu objek kreatifitasnya yang muncul akibat krisis ekonomi. Mulanya ide-ide tersebut diciptakan agar masingmasing komunitas pencinta clothing dapat bertahan hidup, namun kenyataannya keunikan ide ekletik mereka mampu bertahan sampai ke fase 10 tahun kedua.

Globalisasi informasi yang deras memasuki ruangruang keseharian komunitas urban kreatif yang kental dengan gaya hidup dan budaya urban ini mempengaruhi gaya pikir, standar selera, kemas- an komunikasi dan pergaulan serta aktivitas keseharian, seperti kegiatan berkesenian, musik, olahraga ekstrim, bahkan lebih jauh lagi mulai memasuki wilayah ekspresi tubuh sebagai media ungkapan (body piercing \& tattoo). Hal tersebut tampaknya membentuk sebuah attitude disertai independensi tersendiri dengan segala bentuk ungkapan ekspresi yang unik. Mereka mengolah elemen desain bahkan material yang ada menjadi objek-objek visual baru yang memiliki keunikan dan menonjolkan ciri dari masing-masing komunitasnya, salah satunya dalam bidang fashion.

Keunikan dan ciri khas tersebut memunculkan pengertian fashion sebagai sebuah ideologi yang kemudian membentuk sistem dominan dan 
dominasi yang dalam pemasaran produk akan memunculkan positioning produk.

Seperti layaknya manusia yang beridealisme, clothing pun demikian, masing-masing dari mereka tidak ada satupun yang rela dikatakan sama dengan yang lain. Hal ini kemungkinan berkaitan dengan wacana postmodern mengimbas ke dunia pemasaran. Dalam konsumsi postmo, objek tidak lagi terikat pada logika utilitas, fungsi, kebutuhan, namun melakukan manifes dalam tanda. Tanda-tanda ini dimobilisir dalam bentuk komoditi berdasarkan logika perbedaan. Implikasinya, kebutuhan bukan lagi terhadap objek, tetapi terhadap perbedaan. Orang ingin ditandai secara berbeda baik makna sosial, status, simbol, atau prestise, yang membawa manusia untuk tak terikat lagi pada sebuah makna dan identitas yang tetap. Manusia lantas akan mencari perbedaan dan tak mau disamakan dengan yang lain. Hal tersebut akan memunculkan apa yang disebut alternatif atau diferensiasi. Kesempatan ini dimanfaatkan oleh kapitalisme, sehingga clothing yang awalnya merupakan sebuah alternatif menjadi sebuah produk yang harus memiliki diferensiasi agar dapat mengikuti arus budaya mainstream dengan membangun identitas yang berbeda dengan yang lain. Hal ini dilakukan dengan tujuan untuk bertahan dalam hal pemasaran produk sekaligus mempertahankan ideologi produknya di mata konsumen. Hal diataslah yang kemudian memunculkan apa yang dinamakan diferensiasi ideologi, yang nantinya akan memunculkan positioning produk postioning menurut Kotler diartikan sebagai tindakan yang dilakukan marketer untuk membuat citra produk dan hal-hal yang ingin ditawarkan kepada pasarnya berhasil memperoleh posisi yang jelas dan mengandung arti dalam benak sasaran konsumennya (Philip Kotler, 1997).

Berdasarkan pemaparan singkat diatas ingin diteliti melalui analisis deskriptif kualitatif untuk mengetahui ideologi visual pada sebuah produk clothing yang dibentuk oleh produsen dimata konsumennya, yang mana hal tersebut kemudian akan membentuk positioning produk bersangkutan. Penelitian ini difokuskan pada konsumen Unkl/347 yang mengunjungi distribution outlet nya yang berada di Bandung.

\section{Ideologi Visual}

Mengutip pendapat Banindro, secara singkat Ideologi visual diartikan sebagai sebuah sistem nilai yang ditampakkan atau divisualkan, yang mana di dalam ideologi itu sendiri style dan budaya itu termaktub di dalamnya (Banindro, 2007:72). Sedangkan menurut Nicos Hadjinicolaou Ideologi Visual adalah cara tertentu elemenelemen formal dan tematik satu gambar dipadukan pada satu keperluan yang khusus. Komposisi Gambar merupakan satu bentuk khusus ideologi kelas sosial secara menyeluruh, melalui gambar individu dapat mengkaitkan kehidupan mereka dengan kondisi eksistensi mereka. Ideologi visual berkaitan erat dan tidak dapat dipisahkan dari gaya sebuah kelompok sosial (Yasraf, Saidi, 2009).

\section{Fashion dan Ideologi}

Fashion sebagai ideologi merupakan cara bagi sekelompok orang dibentuk sebagai kelompok sosial untuk mengkomunikasikan identitasnya, dan juga menjamin berfungsinya suatu sistem posisi dominan dan didominasi didalam suatu tatanan sosial. Sebagai ideologi fashion memiliki arti bahwa fashion merupakan bagian dari proses yang didalamnya kelompok sosial membangun, menopang, mereproduksi posisi kekuasaan, serta relasi dominasi dan didominasi yang dibuat kelihatan sepenuhnya alami, tepat dan absah. Bila posisi dominan dan didominasi yang muncul dan yang dialami ini dianggap absah dan alami, maka posisi tersebut bisa diterima atau ditentang, bukan baik oleh orang-orang yang berada dalam posisi dominan, juga oleh mereka yang berada dalam posisi didominasi. Misalnya: Punk, bisa dipahami sebagai suatu fenomena ideologis yang eksplisit yang terlihat dari kalung rantai, tas gombrang, pakaian rongsokan yang murahan, yang merupakan serangan ideologis terhadap nilai estetis kelas dominan. Dalam hal ini Fashion dijadikan sebuah senjata ideologis, satu kumpulan ide, dibuat untuk melawan kumpulan ide lainnya, yakni ideologi lain (Barnard, Ibrahim, 2009: 57-59).

\section{Popular Art}

Popular Art (Pop Art) muncul karena protes terhadap international school dan fungsionalisme yang menggugat desain yang punya nilai estetik selamanya sementara barang yang diproduksi memakai pendekatan relatif. Menurut mereka estetika barang konsumtif harus berangkat dari budaya populer. Kata populer berasal dari Yunani yang artinya 'populis' (rakyat). Aliran ini mendukung media massa yang populer seperti Koran, iklan, televisi, komik, supermarket. Pop Art marak di Amerika dan Inggris dengan tokohnya Andy Warhol, Roy Lichenstein dan di Inggris David Hockney (Meggs, 1986; Heller, 1988). 


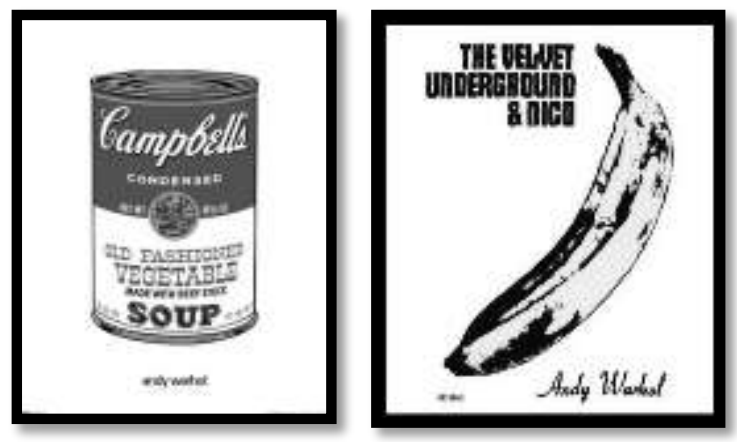

Gambar 1. Contoh Budaya Pop Art-Andy Warhol

\section{Alternatif VS Deferensiasi}

Dalam masyarakat saat ini terdapat sebuah gaya hidup yang berbeda, bertujuan membedakan diri dan menunjukkan sebuah pola konsumsi yang berlandaskan pada perlawanan terhadap mainstream. Pola konsumsi inilah yang kerap kali dikenal dengan sebutan alternatif. Perlawanan ini menolak identitas-identitas yang ditawarkan oleh para pemegang modal. Orang-orang yang berada pada gaya hidup alternatif ini melakukan penolakan dan perlawanan terhadap strategi pemasaran yang dilakukan oleh pemegang modal untuk menguasainya. Alternatif bisa dikatakan sebagai sebuah diferensiasi karena esensinya sama-sama berorientasi pemasaran. Bedanya, alternatif memiliki semangat perlawanan dan reistensi terhadap apa yang menjadi mainstream. Alternatif berusaha membangun identitasnya dengan melakukan identifikasi pada identitas-identitas yang dibangun dan eksis di kalangan mainstream.

Gaya hidup masyarakat saat ini selalu berupaya membuat diri eksis dalam cara tertentu dan berbeda dari yang lain. Hal ini mendorong suatu perilaku konsumsi yang selalu dahaga dan tak terpuaskan, yang mana hal tersebut dengan cerdik dibangkitkan oleh produsen melalui pencitraan yang menjadi titik sentral perumus hubungan sosial. Citra kemudian menjadi bahasa komunikasi sosial dalam masyarakat, yang di dalamnya telah diciptakan klasifikasi dan perbedaan sosial menurut kelas, status, dan selera. Orang mengkonsumsi untuk membentuk style tertentu dalam diri, juga membangun citra tertentu, menggapai gaya hidup yang memapankannya dalam hal-hal yang dianggap bernilai dalam kultur masyarakatnya (Adlin, 2006: 108-111).

Chaney mengungkapkan bahwa identitas sosial disampaikan melalui tiga cara. Pertama, disampaikan dengan menggunakan istilah pilihanpilihan (choices); Sikap, nilai, dan cita rasa yang merupakan karakteristik anggota kelompok sosial ini, diidentifikasi dengan sendirinya sebagai hal yang penting. Sehingga bisa diterima bahwa cita rasa seseorang merupakan tanggung jawab terhadap penilaian orang lain. Implikasinya, kemudian menjadi bagian integral dari suatu perasaan identitas. Kedua, pilihan-pilihan tersebut adalah pilihan kultural, atau lebih persisnya, terfokus pada wilayah-wilayah kehidupan yang merupakan bagian dari aktivitas waktu luang (leisure) atau konsumsi. Ketiga, betapa pun personalnya nilai-nilai dan cita rasa yang diekspresikan, mereka jatuh ke dalam pola-pola khusus yang akhirnya menghubungkan mereka sendiri dengan karakter sosio-struktural lainnya. (Chaney, 2004: 41-43)

\section{Pembahasan}

\section{Unkl/347}

Salah satu clothing brand Bandung Unkl/347 yang mulanya bernama eat/347 Dibentuk oleh sekelompok anak muda Bandung yang terinspirasi dari musik; sebagai refleksi dari budaya pop, eat/347 menciptakan serangkaian desain dengan ikon pop yang diparodikan. Mereka sangat tertantang untuk mengkombinasikan ikon pop dengan sesuatu yang ingin dipakai. Koleksi eat/347 selalu mencoba mendeskripsikan representasi dari ikon pop anak muda dari berbagai era. Pembentukan ideologi visualnya kebanyakan terinsiprasi dari musik dan ikon pop. Misalnya, dalam penciptaan produk yang dikhususkan untuk para gadis remaja, "eat and Nico", berbasis dari Andy Warhol dalam kolaborasi projeknya di akhir tahun 60-an" The Velvet Underground" and "Nico"; Alternative rock band Jesus and The Mary Chain menjadi "eat and The Mary Chain"; Brithis Post-punk Echo and the Bunnymen menjadi "eat and the Bunnymen" dan masih banyak lagi.

Selain itu eat/347 juga mengkomuniasikan ideologi visualnya dengan menampilkan typografi-typodriver pada visual produknya, berisi tentang tehnik penciptaan visual produk tersebut.

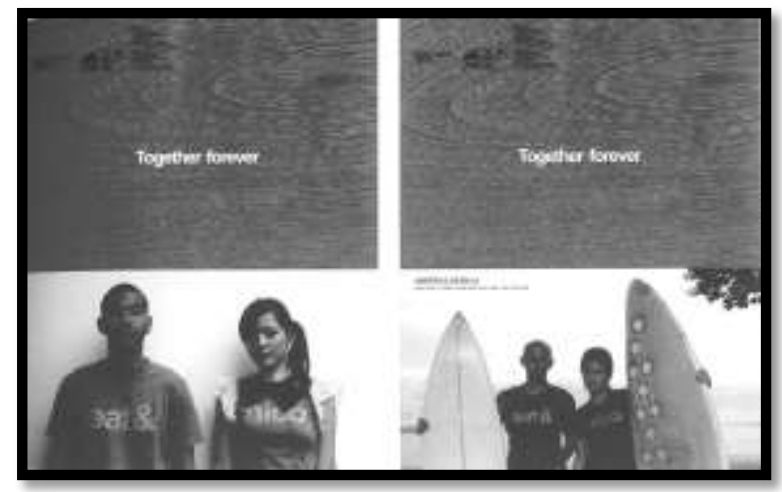

Gambar 2. Promotion ad. "Eat \& Nico". 
Misalnya, "I Xeroxed, Avant Garde, Floppy, Friends and Eat”. Objek Xerox adalah periode saat mereka senang bermain-main dengan teknik fotocopy. Penggunaan kaleng bekas sebagai kemasan sabuk. Masih banyak ide-ide lain yang berhubungan dengan budaya pop anak muda dan ikon-ikonnya yang diangkat oleh eat/347 sebagai ideologi visual mereka. Idenya sederhana, friendly, kreatif, nakal, dan up to date.

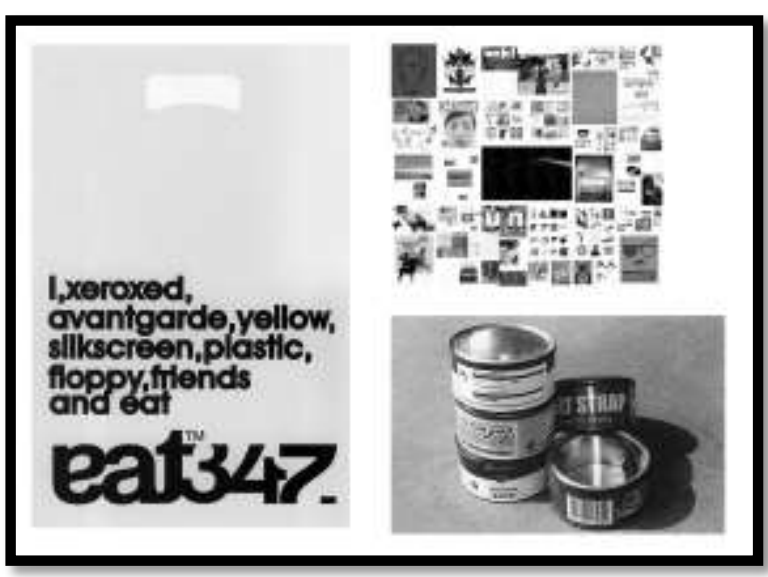

Gambar 3. Typodriver, kaleng bekas sebagai kemasan sabuk.

Ideologi tersebut juga diperkuat dengan Environmental Graphic Design pada retailnya, dan kegiatan-kegiatan yang dilakukan, seperti pembuatan Pemasangan iklan di media-media promosi, pembuatan Ripple Zine, pembuatan Art Book bahkan Recording audio. Hal tersebut dilakukan eat/347 tidak lain adalah untuk menunjukkan dominasinya yang diperlihatkan lewat eksistensi komunitasnya.

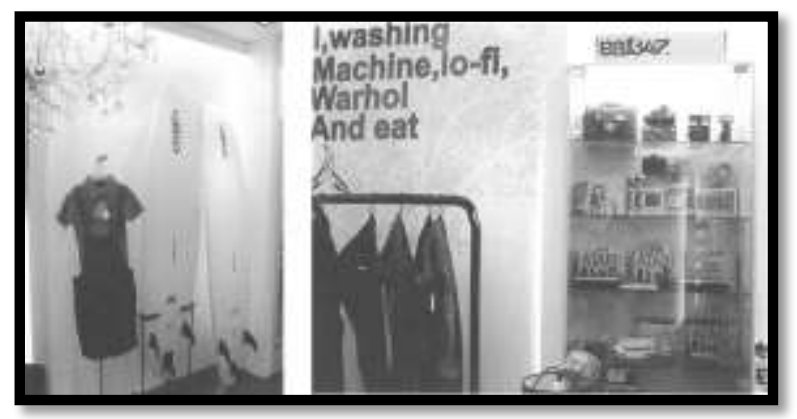

Gambar 4. Environmental graphic design retail eat/347

\section{Penerapan Ideologi Visual eat/347 pada Varian Logonya}

Konsep ide yang sederhana, friendly, kreatif, dan up to date diperlihatkan eat/347 melalui logonya. Logogram eat/347 berbentuk mangkok memiliki konsep "We are What We Eat" yang diadaptasikan dan diparodikan dengan berbagai macam ikon pop yang dekat dengan anak muda.

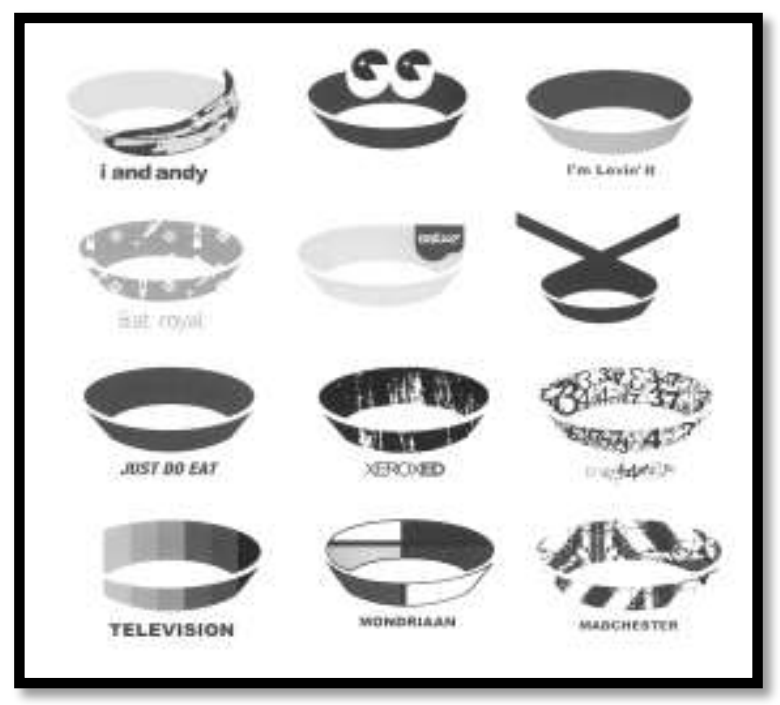

Gambar 5. Penerapan logogram eat/347 dalam parodi berbagai ikon pop anak muda

\section{Diferensiasi pada Produk Unkl/347}

Setelah 12 tahun, eat/347 berubah nama menjadi Unkl/347, terciptalah tag line "After Ten Years Friends Call Us Uncle" tagline ini merayakan kedewasaan eat/347 sebagai sebuah clothing. Unkl/347 tetap dengan konsep "Membuat sesuatu yang ingin dipakai" dan pendekatan ideologi budaya pop yang diparodikan.

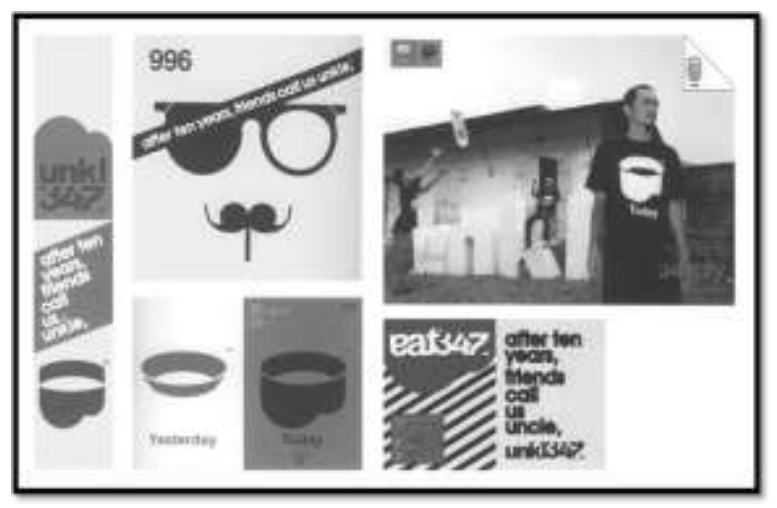

Gambar 6. eat/347 yang berubah menjadi Unkl/347 dengan ideologi

Unkl/347 melakukan diferensiasi dengan cara membangun ideologi visual mereka berbasiskan estetika postmodern dengan pengolahan ikon pop dunia pada produknya yang dikombinasikan menjadi sesuatu yang ingin dipakai. Diferensiasi yang dilakukan oleh Unkl/347 dilakukan untuk bersaing dengan produk clothing lainnya, sekaligus memperkuat ideologi visual Unkl/347. Bila dipandang dari sisi originalitas hal tersebut dirasa sangat tidak orisinil, namun tidak boleh dilupakan bahwa Unkl/347 adalah sebuah clothing yang muncul akibat budaya postmodern yang estetikanyapun adalah estetika postmodern yang cen- 
derung majemuk (polysemy). Namun hal tersebut bila secara konsisten dilakukan akan membuahkan positioning produk, sehingga produkpun akan memiliki segmentasi pasar yang jelas.

Paparan diatas mengungkapkan bahwa melalui visual yang ditampilkan oleh Unkl/347 budaya $P o p$ Art ditampakkan, kemudian secara halus berhasil memaksa konsumen untuk tampil dengan gaya tersebut. Saat konsumen Unkl/347 menggunakan produknya dapat diartikan mereka mengkaitkan kondisi eksistensinya dalam sebuah gaya kelompok sosial Pop Art yang dibangun oleh Unkl/347. Hal tersebut membenarkan bahwa Unkl/347 telah berhasil membangun ideologi visual melalui produknya. Melalui ideologi visual yang dibangun, diferensiasi produk ditampakkan, sehingga membentuk positioning Unkl/347 sebagai sebuah clothing brand indie yang mengangkat tema budaya Pop Art dengan pendekatan postmodern.

\section{Analisa Elemen Desain Unkl/347}

- Tipografi yang dipakai dalam aplikasi produknya bebas, dekonstruktif, disesuaikan dengan ikon pop yang diambil

- Warna yang dipakai solid, disesuaikan dengan ikon pop yang diambil

- Gambar yang dipakai dalam bentuk vektor, disesuaikan dengan ikon pop yang diambil.

- Layout yang dipakai dekonstruktif, berkesan main-main, disesuaikan dengan ikon pop yang diambil.

- Secara garis besar desain yang dimunculkan berdasarkan estetika postmodern.

\section{Ideologi yang Ingin Dikomunikasikan oleh Unkl/347 sebagi produsen}

Berdasarkan wawancara dengan desainer Unkl /347, dalam pembuatan desainnya-pun terkadang mereka mengalami sesuatu yang blur, karena sangat banyaknya budaya pop yang ada; kebingungan juga terjadi saat menentukan mana yang harus diangkat untuk dijadikan ide visualisasi produk mereka, tetapi Unkl/347 tetap konsisten pada ideologi produk mereka yaitu "membuat sesuatu yang muda, pop dan yang ingin pakai". "Forget our ever older age, let's just love one another and be young forever"

Konsistensi ideologi yang dikomunikasikan diperlihatkan dengan mengusung tinggi estetika postmodern yang sarat dengan ekletikisme, dekonstruksi, parodi, pastiche dengan cara mengadopsi ikon-ikon pop dunia dan mengawinkannya dengan identitas Unkl/347, melahirkan sebuah desain yang unik dan memiliki identitas tersendiri.

\section{Ideologi yang Diterima oleh Konsumen Unkl/347}

Setelah melakukan pengumpulan data dengan cara pembagian kuesioner pada para pemakai produk Unkl/347 yang tergabung dalam sebuah kelompok grup diskusi (FGD) didapat data, bahwa sebagian besar konsumen menyukai produk Unkl/347 bukan karena mereka benar-benar memahami arti dari pengadopsian ikon pop tersebut pada produk Unkl/347. Bahkan ada sebagian kecil yang beranggapan Unkl/347 membonceng kepopuleran dari ikon pop dunia tersebut, namun ada juga yang beranggapan positif yang menyatakan bahwa hal tersebut adalah kreatifitas Unkl/347 dalam mengolah ikon pop dunia yang ada untuk memperkuat logo mangkok dimata konsumen. Namun walaupun demikian menurut mereka desain-desain Unkl/347 adalah sebuah desain yang kreatif, keren, mempunyai ciri khas dan komunitasnya tersendiri, tidak pasaran, bahannya nyaman dipakai, serta dapat bersaing dengan produk impor yang ada.

\section{Kesimpulan}

Ideologi visual dalam clothing muncul karena idealisme pencipta produk clothing tersebut. Ideologi yang ditanamkan melalui desain pada clothing mampu menciptakan sebuah dominasi yang diperlihatkan melalui eksitensi para konsumen pemakai clothing tersebut. Pembentukan ideologi pada clothing tidak terlepas dengan adanya komunitas yang mendukung terserapnya ideologi tersebut sebagai sebuah karakteristik kelompok tertentu.

Benarlah yang diungkapkan oleh Chaney, bahwa sebuah identitas sosial yang disampaikan walaupun mengandung nilai-nilai personal dan cita rasa yang diekspresikan, akan jatuh ke dalam pola-pola khusus yang akhirnya menghubungkan masingmasing personal dengan karakter sosio-struktural lainnya dalam sebuah komunitas.

Walaupun Unkl/347 hanya mengolah ikon pop dunia yang sudah ada dan menciptakan sebuah estetika postmodern dalam produknya, sebagai salah satu clothing brand indie Unkl/347 cukup berhasil membentuk ideologi visualnya dan berhasil mem-posisikan produknya sebagai sebuah clothing brand indie yang berjiwa muda, kreatif, keren, mempunyai ciri khas dan komunitasnya tersendiri, tidak pasaran dan nyaman dipakai sehingga dapat bersaing dengan produk impor yang ada. Hal tersebut mengungkapkan bahwa Ideologi visual dapat menjadi salah satu faktor penting dalam membentuk positioning sebuah produk. 


\section{Daftar Pustaka}

Banindro, S. Baskoro (2007). Gaya Psychedelia Counter Culture Amerika Komodifikasi Indonesia Kini. Surabaya: NIRMANA, Vol. 9, No. 2.

Barnard, Malcolm. (1996). Fashion Sebagai Komunikasi: Cara mengkomunikasikan identitas sosial, seksual, kelas dan gender. Yogyakarta: Jalasutra.

Kasali, Rhenald. (1998). Membidik Pasar Indonesia: Segmentasi, Targeting dan Positioning. Jakarta: PT.Gramedia Pustaka Umum.
Audifax. Adlin Alfathri. (2006). Resistensi Gaya Hidup: Teori dan Realitas. Yogyakarta: Jalasutra.

UNKL/347. After Ten Years They Call Me Uncle Art book. Bandung

Piliang. A. Yasraf . Saidi. I. Acep. (2009). Desain \& Ideologi. Bandung: ITB

Almakki, Zamzami. (2009). Distro dan gaya hidup anak muda masa kini. Diunduh 26 Oktober 2009 dari http://zamzami-almakki.blog.frienster. com/2008/11. 